\title{
Priority Setting in Health Research in Cuba, 2010
}

\author{
Mayra Álvarez MS, Leticia Artiles MS PhD, Jacinta Otero MD, Niviola Cabrera MD
}

\begin{abstract}
In public health systems, priority setting in health research determines resource allocation to produce evidence and proposals aimed at solving the population's health problems. In Cuba, the Science and Technical Division (S\&T) of the Ministry of Public Health (MINSAP) leads this process, based on the country's health policy framework and consistent with optimal use of resources. To set health research priorities (HRPs) for 2010, a three-stage interpretive method was used involving 215 professionals working at all levels of the health system in 14 territories, 22 MINSAP experts, and academic administrators and health system managers at provincial and national levels. In Stage I, HRPs were identified and confirmed in each territory using a nominal group technique and ranked using the Hanlon Method. Further classification, ranking and ratification in Stages II and III resulted in a final set of five HRPs defined in the annual Request for Proposals from which projects are selected for funding. Results reflected consensus on the need to prioritize research on determinants of low risk perception and on program management. The participatory process laid the groundwork for conducting research better designed to contribute to solutions to major health problems affecting the Cuban population.
\end{abstract}

KEYWORDS Research priorities, health services research, national health policy, Cuba

\section{BACKGROUND}

Fulfilling the health needs of a country's population requires substantial resources. Public health systems worldwide rarely have at their disposal sufficient resources to provide the best possible services to the whole population. Thus, establishing priorities for allocation of available resources designed to achieve greatest social impact, consistent with national health policy, is a fundamental element of public health planning strategies.[1-6] Systematic reassessment of health research priorities is also needed to facilitate agenda-setting that makes optimal use of resources and is most likely to ensure solutions to the population's main health problems.[2-4,7-9]

National public health systems in different countries use various methods for setting health research priorities (HRPs).[3,6-9,10] These tend to be technical or interpretive. The former are based on epidemiological or economic data; for example, disease prevalence or the cost of a particular treatment or technology. The latter apply criteria derived primarily from consensus methods involving a range of stakeholders. These more qualitative approaches are being applied more widely; Argentina, Brazil and Peru, among others in Latin America, have used interpretive methods to set their HRPs.[6-7,9] Interpretive methods are particularly suited to addressing diverse objectives and considering multiple opinions, which is why they have been used mainly by government agencies needing to assess lines of research in very different fields. On the other hand, results of these methods rely on, and are limited by, the knowledge, experience, representation, and interests of participants.[6-7,9-10]

\section{THE SCIENTIFIC-TECHNICAL APPROACH}

In Cuba, health research priorities are set annually by the Ministry of Public Health (MINSAP) through its Science and Technical
Division (S\&T). The national health research policy framework is currently defined by a strategic plan launched in 2006 entitled Public Health Projections in Cuba for Year 2015. This plan sets concrete targets in eight priority areas (see box) and lines of action aimed at reaching them. With regard to health research, it calls for a stronger focus on health problems in each polyclinic, hospital, and medical school, leading to concrete solutions applied to the principal determinants of the most prevalent or serious conditions affecting the communities in their area. It also emphasizes strengthening MINSAP's Scientific and Technological Innovation System at the provincial level, thereby transferring best scientific practices from national institutions in the capital to provincial and municipal health services capable of generating more applicable research results.[1]

The Science and Technical Division is charged with implementing this policy, defining national research objectives and health problems prioritized for research. The Division relies on its own staff and an advisory body drawn from 15 Scientific-Technical Program Areas (STPAs) (see box). Each STPA functions as an expert group made up of professionals in a specific field or, in some cases, various fields covered by the program area.[11] One way the STPAs contribute to the national health research prioritysetting process is through systematic updating of area-specific objectives in accordance with the health situation of the population, evidenced by epidemiological indicators and other factors.

The mechanism employed by MINSAP for allocating health research funding is an annual Request for Proposals (RFP) for scientific research and innovation. Prior to the process begun in 2009, the S\&T Division defined the HRPs addressed in the RFP, relying on STPA input and evaluation, and taking into consideration the targets and lines of action established in MINSAP's strategic plan.[12]

This resulted, however, in a broad range of HRPs that did not facilitate allocation of resources to research proposals with the greatest potential for contributing solutions to the most prevalent and severe health problems, particularly in the current context of economic constraints. Therefore, to establish HRPs for the 2010 RFP, the Division decided to undertake an interpretive priority setting process beginning with identification of health problems from the perspective of practitioner/researchers at all levels of care in each of the country's 14 provinces.

\section{INVOLVING STAKEHOLDERS FROM THE POLYCLINIC TO THE PUBLIC HEALTH MINISTRY}

The health research priority-setting process for 2010 was carried out in three stages between July 2009 and January 2010. The national S\&T Director, two S\&T methodologists, and a consultant with the Agency for Knowledge Generation and Technology of the Ministry of Science, Technology and the Environment (hereinafter S\&T team) designed and conducted the process.

Stage I (July-September 2009)

A total of 215 health professionals from 13 of the country's 14 provinces and the Isle of Youth Special Municipality (territories) 


\section{Scientific-Technical Program Areas (STPAs), Cuban Ministry of Public Health}

- Women's and Children's Health

- Quality of Life

- Infectious Diseases

- Non-communicable Chronic Diseases (excluding cancer) and Accidents

- Cancer

- Comprehensive Family Health Care

- Health Systems and Services

- Medicines and Biodiagnostic Technologies

- Evaluation of Health Technologies

- Natural and Traditional Medicine

- Comprehensive Older-Adult Services

- Health Information Technology

- Health Products \& Services: Safety, Protection, Surveillance

- Human Resources Development in Health Care

- Health Worker Health

\section{Strategic Priorities, Cuban Ministry of Public Health, 2006-2015*}

- Environmental factors affecting health (water, sanitation, vectors)

- Behavioral factors affecting health (smoking, alcohol abuse, drug abuse, diet $\&$ nutrition, sedentarism)

- Non-communicable diseases and other health problems (hypertension, ischemic heart disease, cancer, cerebrovascular disease, diabetes mellitus, chronic kidney disease, chronic respiratory diseases, mental health problems and self-inflicted injuries, injuries from accidents or aggression, preventable blindness, degenerative bone and joint disease)

- Oral health

- Emerging and re-emerging communicable diseases (influenza and pneumonia, STI/HIV/AIDS, acute diarrheal diseases, hepatitis-A, nosocomial infections; also maintaining eradication or continued reduction of diphtheria, whooping cough, neonatal tetanus, measles, poliomyelitis, rubeola, mumps, tuberculosis, leptospirosis, rabies, meningitis meningococica, Haemophilus influenza B, leprosy, tetanus, and syphilis; and prevention of malaria, dengue, SARs, avian influenza, West Nile virus, and cholera)

- Disability (low vision rehabilitation, early screening for hearing loss, injury rehabilitation)

- Special environments (schools, workplaces)

- Special groups (pediatric age group, women, older adults)

* Public Health Projections in Cuba for Year 2015

participated in the first stage of the process. Pinar del Río Province, scheduled for September, was not included due to logistical difficulties. The S\&T Department at the medical university leading science and technological innovation in each territory served as coordinator and selected the participants. These groups were representative of diverse professions (physicians, nurses, psychologists, educators, sociologists, dentists, health technologists, engineers, biologists, microbiologists, pharmacists, among others) and functions (clinical care; research; teaching; administration; and S\&T management in primary, secondary, and tertiary care, provincial health departments, or the university). All participants were actively involved in health research.

Participants in each territory attended one or two all-day meetings (depending on location) led by members of the S\&T team.
These sessions began with an introductory presentation about MINSAP's Scientific and Technological Innovation System, strategic plans, and health research policy.

Participants were next divided into two groups using a nonprobability, maximum variation design to ensure heterogeneity within each group and homogeneity between groups.[13-14] In the activities that followed, a nominal group technique was used to obtain and validate information.

The first group, called the "identification" group, was asked to identify health research priorities in their spheres of activity. Priority was defined as a health problem that could feasibly be addressed through research and provide results contributing to the problem's total or partial solution; criteria also considered the importance of the problem for individual patients, the population, and health professionals, consistent with MINSAP objectives.

Once the group understood the purpose of the process, the moderator posed the initial question:

"Which health problems merit research, the results of which could enrich practices leading to their partial or complete solution?"

Each participant had 15 minutes to write a list of the health problems he or she considered priorities. Each then read his/her list aloud, and the problems identified were projected by the moderator to be visible to the whole group. A brief discussion followed to clarify the content of all problems presented and to merge similar ones. At this stage, validity of problems was not compared, and none were rejected.

The second, "confirmatory" group had the task of confirming or rejecting the health problems identified as research priorities by the identification group. The moderator described the preceding activity and, after explaining the confirmatory group's objective, presented the health problems identified by the first group. Using the same methodology, based on the initial question, this group confirmed or rejected the previous group's proposals.

The HRPs identified by the first group and confirmed by the second group were ranked using the Hanlon Method, $[4,15]$ which is based on four components applied as follows:

Component $A$ : Magnitude of the health problem

Component B: Severity of the problem

Component $C$ : Effectiveness of the solution (capacity of research results to contribute a total or partial solution to the problem identified)

Component D: Feasibility of conducting research (To be considered feasible, the following conditions must be met: research is appropriate for solving the problem; the economic, human, and material resources for conducting the research are available; research presents no ethical or legal problems if conducted in authorized MINSAP institutions; the research is acceptable to everyone directly and indirectly involved in conducting it and in using the results.)

The score is determined by the following formula: $(A+B) C \times D$.

The results established HRPs in each territory. A total of 160 HRPs were confirmed by participants in all 14 territories in Stage I. Priorities identified in only one territory $(54 ; 33.75 \%)$ 
were classified "local" priorities, and the rest (106; 66.25\%), identified in at least two territories, became "shared" priorities. The S\&T team reviewed the content of the shared HRPs and merged them into 15 research areas, which were then ranked in priority by averaging the scores obtained using the Hanlon Method (Table 1).

\section{Table 1: Health Research Priorities Identified and Ranked by Provincial Health Professionals}

\section{Research Priorities ${ }^{\mathrm{a}}$}

Identification of insufficiencies in management processes and [understanding of] the social, biological, and cultural causes related to low risk perception of non-communicable chronic diseases.

Determinants of low risk perception among health personnel and the general population of preconception factors in women's health associated with low birth weight, morbidity from chronic non-communicable diseases among pregnant women, as well as neonatal infection and vaginal sepsis. Identification of the causes of insufficiencies influencing the organizational management of the Program for Comprehensive Care for Women and Children (PAMI, its Spanish acronym)

Insufficient quality of service provision and professional performance, with the resulting inadequate attention to patients and users.

Determinants related to sustained high prevalence of dental caries, periodontal disease and malocclusions.

Identification of insufficiencies in the quality of comprehensive human resources training: recruitment, enrollment, development, and impact on the health system.

Low risk perception in the general population of the consequences of high infestation rates of the Aedes aegypti mosquito.

Low risk perception of behaviors associated with an increase in morbidity from sexually transmitted infections (STIs). Low risk perception of behaviors associated with an increase in teen pregnancy and abortion.

Identification of social, cultural, psychological, economic, and biological factors determining the increased incidence and prevalence of alcoholism and other addictions in adolescents and young adults, and their relation to antisocial and criminal behaviors.

Improvement of the Older Adult Program for comprehensive attention to seniors in the context of an aging population.

Sociocultural, environmental, biological, geographic, economic, and service provision determinants associated with low risk perception and late diagnosis of breast, lung, hematologic, colon, prostate, esophageal, and cervical cancers in ever-younger age groups, with the resulting sustained increase in morbidity and mortality.

Psychological, sociocultural, environmental, biological, geographic, economic, and service provision determinants associated with low risk perception related to increased morbidity and mortality from cardio- and cerebrovascular diseases at younger ages (behavioral changes in lifestyles that do not protect health).

Determinants that play a role in high mortality from accidents in children and adolescents, and from traffic accidents.

Socioeconomic, cultural, environmental, biological, and psychological factors associated with suicidal behavior.

adentified in at least two territories

b Hanlon Method

Source: Stage I results, health research priority setting process for 2010, Science and Technical Division, Ministry of Public Health, Cuba.
The frequency with which the shared priorities were mentioned was also taken into account. The most frequent priorities, identified in 11 territories, were: identification of insufficiencies in the quality of comprehensive human resources training, and determinants associated with low risk perception and late diagnosis of cancer at different sites in ever-younger age groups.

\section{Stage II (October 9, 2009)}

The S\&T Director, in collaboration with the STPAs, convened an expert meeting on October 9, 2009 to assess relevance of conducting research to provide solutions to the health problems identified as shared priorities in Stage I. Twenty-two experts participated. The group was representative in terms of profession (medical and non-medical) and function (MINSAP methodologists, administrators, clinicians, and researchers).

The moderator explained the objectives of the priority setting process and Stage I activities, and presented the 15 shared HRPs (without results of the prioritization exercise). The expert group was asked to confirm or reject those HRPs, and to recommend other health problems they considered national research priorities. By means of consensus, the group ratified all $15 \mathrm{HRPs}$ and did not propose any additions.

Participants were then asked to individually assess in writing the relevance of conducting research to solve each of the $15 \mathrm{HRPs}$, considering to what degree research and its outcomes would contribute to solving each health problem at the national level. A 5-point scale was used with 5 indicating highly relevant and 1 , not relevant. The S\&T team then averaged resulting scores and ranked the HRPs according to relevance (Table 2).

\section{Stage III (October 16, 2009-January 11, 2010)}

In this final stage of the priority setting process, the S\&T team took into consideration the outcomes of the previous stages and consulted opinions of MINSAP national and provincial academic administrators and health system managers, plus S\&T methodologists.

On October 16, 2009, an S\&T team member presented results of Stages I and II at the national meeting of rectors and deans of medical and allied health sciences schools. This meeting was chaired by the Vice Minister of Health for Education and Research and was attended by the rectors of Cuba's 13 medical universities, the deans of the medical schools in Havana Province and the Isle of Youth Special Municipality, the national directors of undergraduate and graduate medical education, the director of the S\&T Division, and national teaching and research methodologists. There were 24 participants in the group.

A similar meeting was held on October 23, 2009, to present Stage I and II results to the 23 members of the Health Minister's Advisory Council, along with the Vice Ministers of Health and provincial health department directors. Participants in both meetings ratified the shared HRPs as health problems requiring research for their solution.

The S\&T team then met with seven S\&T methodologists to define HRP selection criteria for the health research RFP for 2010.

The resulting criteria were:

a) HRPs identified in Stage I with over $50 \%$ of the maximum score obtained using the Hanlon Method and 4 points or above on the relevance scale in Stage II. 
b) HRPs most frequently identified in Stage I, independent of score.

c) HRPs proposed by the S\&T team, considering health problems stated in the MINSAP Priorities and Work Objectives for 2010 that research will significantly contribute to solving.[16]

Table 2: Relevance of Health Research Priorities Rated by Scientific and Technical Program Area Experts

\section{Research Priorities $^{a}$}

Average

Score $^{b}$

Sociocultural, environmental, biological, geographic, economic, and service provision determinants associated with low risk perception and late diagnosis of breast, lung, hematologic, colon, prostate, esophageal, and cervical cancers in ever-younger age groups, with the resulting sustained increase in morbidity and mortality.

Psychological, sociocultural, environmental, biological, geographic, economic, and service provision determinants associated with low risk perception related to increased morbidity and mortality from cardio- and cerebrovascular diseases at younger ages (behavioral changes in lifestyles that do not protect health).

Identification of insufficiencies in the quality of comprehensive human resources training: recruitment, enrollment, development, and impact on the health system.

Identification of social, cultural, psychological, economic, and biological factors determining the increased incidence and prevalence of alcoholism and other addictions in adolescents and young adults, and their relation to antisocial and criminal behaviors.

Identification of insufficiencies in management processes and [understanding of] the social, biological, and cultural causes related to low risk perception of non-communicable chronic diseases.

Insufficient quality of service provision and professional performance, with the resulting inadequate attention to patients and users.

Improvement of the Older Adult Program for comprehensive attention to seniors in the context of an aging population.

Low risk perception of behaviors associated with an increase in morbidity from sexually transmitted infections (STIs).

Low risk perception in the general population of the consequences of high infestation rates of the Aedes aegypti mosquito.

Determinants that play a role in high mortality from accidents in children and adolescents, and from traffic accidents.

Socioeconomic, cultural, environmental, biological, and psychological factors associated with suicidal behavior.

Identification of the causes of insufficiencies influencing the organizational management of the Program for Comprehensive Care for Women and Children (PAMI, its Spanish acronym).

Determinants of low risk perception among health personnel and the general population of preconception factors in women's health associated with low birth weight, morbidity from chronic non-communicable diseases among pregnant women, as well as neonatal infection and vaginal sepsis.

Low risk perception of behaviors associated with an increase in teen pregnancy and abortion.

Determinants related to sustained high prevalence of dental caries, periodontal disease and malocclusions.

Identified in Stage I (Table 1)

b Scale of 1 to $5,1=$ not relevant, $5=$ highly relevant

Source: Stage II results, health research priority setting process for 2010, Science and Technical Division, Ministry of Public Health, Cuba.
Based on the first two criteria, the following were selected as national research priorities:

- Insufficiencies in the quality of comprehensive human resources training: recruitment, enrollment, development, and impact on the health system.

- Low risk perception leading to late diagnosis of breast, lung, hematologic, colon, prostate, esophageal, and cervical cancers in ever-younger age groups, with the resulting sustained increase in mortality.

- Social, biological, and cultural factors associated with low risk perception of non-communicable chronic diseases.

- Insufficient quality of service provision and professional performance resulting in inadequate attention to patients and users.

Based on the third criterion, the following priorities were added:

- Low risk perception leading to inappropriate sociocultural lifestyle behaviors hindering control of diseases that increase maternal morbidity and mortality rates.

- Social, biological, cultural, and environmental factors related to low risk perception of nationally prioritized communicable diseases.

Participants in the October meetings were informed via e-mail of the final national HRP selection process, and the S\&T Division's proposals were ratified by all those consulted, thereby establishing Cuba's national HRPs for 2010 (Table 3).

In early December, S\&T Division staff met with the STPA directors to share results of the priority setting process and discuss their implications for defining research objectives for 2010. In the weeks that followed, S\&T methodologists assisted the STPAs in redefining their research objectives in accordance with the new national HRPs. The process culminated on January 11 with official release of the 2010 health research RFP.

Table 3. National Health Research Priorities for 2010, Request for Proposals, Science and Technical Division, Cuban Ministry of Public Health Insufficiencies in the quality of comprehensive human resources training: recruitment, enrollment, development, and impact on the health system.

Low risk perception leading to late diagnosis of breast, lung, hematologic, colon, prostate, esophageal, and cervical cancers in ever-younger age groups, with the resulting sustained increase in mortality.

3.55 Social, biological, and cultural factors associated with low risk perception of non-communicable chronic diseases.

Insufficient quality of service provision and professional performance resulting in inadequate attention to patients and users.

Low risk perception leading to inappropriate socio-cultural lifestyle behaviors hindering control of diseases that increase maternal morbidity and mortality rates.

Social, biological, cultural and environmental factors related to low risk perception of prioritized communicable diseases.

Source: Stage III results, health research priority setting process for 2010, Science and Technical Division, Ministry of Public Health, Cuba.

\section{CONCLUSIONS}

For the first time in Cuba, the public health system applied an interpretive, qualitative approach to set priorities determining the annual allocation of resources for health research. That process enabled professionals-those directly involved in patient care, 
teaching, and research, up to the highest levels of academia and the health system's leadership-to make proposals, offer opinions, and contribute to a final consensus.

This consensus emerged around the need to focus on health research priorities that address socio-cultural, economic, biological, psychological, and environmental determinants related to low risk perception; as well as improvements in program management, including, in some cases revision and updating of program content. These outcomes helped clarify and improve the STPAs' immediate research objectives, essentially reorienting them toward the problem of low risk perception. Furthermore, the local priorities identified in each territory, independent of the national HRPs, serve as a basis for research on health problems that predominate in one geographic area and not in others.

The process also revealed important differences in perspective among stakeholders from different territories and levels of the health system. Ranking of priorities in Stage I, for example, reflected the proximity of those participants to patients and the community-together the main actors implementing programs addressing health problems identified as priorities. At the same time, the gravity of these health problems is influenced positively or negatively by the quality of program implementation. On the other hand, experts participating in Stage II were more involved in program management from a national perspective and therefore ranked the same HRPs in a different order, in terms of relevance of research to solving the identified health problems.

S\&T Division staff concluded that the participatory process used to set national HRPs for 2010 laid the groundwork for conducting research better designed to contribute to solving the Cuban population's most pressing health problems. Limiting the RFP to the final selection of HRPs offers a greater guarantee that resources will be allocated to research projects with the most potential to result in solutions.

\section{ACKNOWLEDGEMENTS}

We are grateful to Dr. María Victoria Norabuena Canal, Science and Technical Division methodologist, for her contribution to implementation of this process. 1 -

\section{REFERENCES}

1. Ministry of Public Health (CU). Proyecciones de la Salud Pública en Cuba para el 2015. Havana: Ministry of Public Health (CU); 2006. 55 p.

2. Alvarez A, Cabrera N. Cuba: financiación de la investigación e innovación en salud. In: Landriaut $E$, Matlin S, editors. Seguimiento de los flujos económicos en la investigación en salud 2009. Tras las cifras mundiales. Geneva: Global Forum for Health Research; 2009. p. 143-53.

3. Agudelo CA, de la Hoz F, Mojica MJ, Eslava JC, Robledo $R$, Cifuentes $P$, et al. Prioridades de Investigación en Salud en Colombia: Perspectiva de los Investigadores. Rev Salud Pública. 2009;11(2):301-9.

4. González J. Texto Básico Asignatura Salud Pública III. Universidad de Chile-Facultad de Medicina-Escuela de Salud Pública, Santiago de Chile: División de Políticas y Gestión en Salud; 2004.

5. Viceministerio de Docencia e InvestigacionesDirección de Ciencia y Técnica. Áreas de Resultados Clave: Gestión en Ciencia e Innovación Tecnológica. Havana: Ministry of Public Health (CU); 2008. p. 42

6. Lomas J, Fulop N, Gagnon D, Allen P. On being a good listener: setting priorities for applied health services research. Milbank Q. 2003;81(3):363-88.

7. Alger J, Becerra-Posada F, Kennedy A, Martinelli E, Cuervo LG. National health research systems in Latin America: a 14-country review. Rev Panam Salud Publica. 2009 Nov;26(5):447-57.

8. Instituto Nacional de Salud (PE). Prioridades de investigación en salud en el Perú: análisis del proceso. Lima: INS; 2007. p. 144.
9. Bernal-Delgado E, Peiró S, Sotoca R. Prioridades de investigación en servicios sanitarios en el Sistema Nacional de Salud. Una aproximación por consenso de expertos. Gac Sanit. 2006;20(4):287-94.

10. Smith N, Mitton C, Peacock S, Cornelissen $\mathrm{E}$, MacLeod S. Identifying research priorities for health care priority setting: a collaborative effort between managers and researchers. BMC Health Serv Res [Internet]. 2009 Sep 15 [cited 2010 Feb 25];9:[about 9 p.]. Available from: www.ncbi.nlm.nih.gov/pmc/articles/ PMC2755472

11. Viceministerio de Salud, Área de Docencia e Investigaciones. Indicación 30/2007. Havana: Ministry of Public Health (CU); 2007. 6 p.

12. Álvarez AS, Cabrera N. Manual de Procedimientos del Sistema de Programas y Proyectos MINSAP. Havana: Dirección de Ciencia y Técnica, Ministry of Public Health (CU); 2008.

13. Artiles L, Otero J, Barrios I. Metodología de la Investigación. Havana: Editorial de Ciencias Médicas; 2008.

14. Bacallao J, Alerm A, Artiles L, Fernández Garrote $\mathrm{L}$. Texto básico de metodología de la investigación educacional. Maestría en Educación Médica. Havana: National School of Public Health (CU); 2004

15. Toledo $H$, Borroto $R$, Flores ML, Núñez C. Determinación de prioridades en salud con participación social. Rev Cubana Med Gen Integr. 1996;12(3):222-8.

16. Ministry of Public Health (CU). Prioridades y objetivos de trabajo. Havana: Ministry of Public Health; 2010. p. 21.

\section{THE AUTHORS}

Mayra Álvarez Corredera (Corresponding author: farmacol@infomed.sld.cu), clinical pharmacist and methodologist, Science and Technical Division, Ministry of Public Health. Associate professor, Medical University of Havana, Havana, Cuba.

Leticia Artiles Visbal, anthropologist with a doctorate in health sciences. Full professor, Medical University of Havana and consultant with the Agency for Knowledge Generation and Technology, Ministry of Science, Technology and the Environment, Havana, Cuba.

Jacinta Otero Iglesias, biostatistician. Associate professor, National School of Public Health. Advisor, Postgraduate Education Department, Medical University of Havana, Havana, Cuba.

Niviola Cabrera Cruz, epidemiologist. Director, Science and Technical Division, Ministry of Public Health. Professor, Medical University of Havana, Havana, Cuba.

Submitted: September 2, 2010

Approved for publication: October 21, 2010

Disclosures: None 